\title{
PERLINDUNGAN KONSUMEN TERHADAP PRODUK KOSMETIK YANG TIDAK TERDAFTAR IZIN EDARNYA DI BPOM SEMARANG
}

\author{
Mufidatul Khasanah, Adi Suliantoro \\ Fakultas Hukum, Universitas Stikubank (UNISBANK) Semarang \\ Email: Mdatu1410@gmail.com, adisuliantoro65@gmail.com
}

\begin{abstract}
ABSTRAK
Tujuan penelitian ini adalah untuk mengetahui Perlindungan konsumen yang menggunakan kosmetik yang tidak terdaftar izin edarnya di BPOM, akibat hukum bagi pelaku usaha kosmetik yang tidak mendaftarkan izin edar produknya ke-BPOM dan solusinya. Metode penelitian yang digunakan Yuridis Normatif, dengan spesifikasi penelitian bersifat Deskriptif Analitis. Perolehan data menggunakan Data Sekunder melalui studi kepustakaan dan Teknik wawancara sebagai pelengkap dari data sekunder yang kemudian dianalisa menggunakan Metode diskriptif kualitatif. Dari hasil penelitian, diperoleh simpulan bahwa akibat hukum bagi pelaku usaha kosmetik yang tidak mendaftarkan izin edar produknya ke-BPOM yaitu sanksi administratif dan sanksi pidana sesuai dengan Pasal 45, pasal 60 dan 62 Undang- Undang Perlindungan Konsumen Nomor 8 Tahun 1999, Pasal 47 Ayat (2) Peraturan Badan Pengawas Obat Dan Makanan Nomor 12 Tahun 2020, Pasal 20 Peraturan Menteri Kesehatan Nomor 1175/Menkes/Per/XII/2010 Tentang Notifikasi Kosmetik, Pasal 98, 106, 196 dan 197, U U Nomor 36Tahun 2009 Tentang Kesehatan. Solusi dari masalah tersebut adalah bahwa pelaku usaha sebelum mengedarkan produk kosmetik yang dihasilkannya diwajibkan untuk mendaftarkan terlebih dahulu produknya ke- BPOM, agar tidak terjadi komplain, gugatan bahkan sanksi pidana.
\end{abstract}

Kata Kunci: Perlindungan Konsumen, Kosmetik, Izin edar, ВPOM

\begin{abstract}
The purpose of this study is to determine the protection of consumers who use cosmetics that are not registered with the BPOM, the legal consequences for cosmetic business actors who do not register their product distribution permits with BPOM and the solution. The research method used was normative juridical, with a descriptive analytical research specification. Obtaining data using secondary data through library research and interview techniques as a complement to secondary data which is then analyzed using descriptive qualitative methods. From the research results, it is concluded that the legal consequences for cosmetic business actors who do not register their product distribution permits with BPOM are administrative sanctions and criminal sanctions in accordance with Articles 45, articles 60 and 62 of the Consumer Protection Law Number 8 of 1999, Article 47 Paragraph (2) Regulation of the Food and Drug Supervisory Agency Number 12 of 2020, Article 20 of Minister of Health Regulation Number 1175 / Menkes / Per / XII / 2010 concerning Cosmetic Notifications, Articles 98, 106, 196 and 197, UUN Number 36 of 2009 concerning Health. The solution to this problem is that before distributing the cosmetic products it produces, business actors are required to register their products with BPOM in advance, so that there are no complaints, lawsuits and even criminal sanctions.
\end{abstract}

Keywords: Consumer Protection, Cosmetics, Distribution license, BPOM 


\section{Pendahuluan}

Pada zaman sekarang ini mempunyai kulit putih, bersih, cerah, tanpa flek hitam dan jerawat merupakan impian bagi setiap kaum wanita. Dengan adanya penyebab inilah Tidak heran banyak kaum wanita maupun laki-aki yang berbondong-bondong untuk mencari produk-produk kosmetik hingga sampai melakukan perawatan kulit agar kulit mereka mejadi bersih dan terhindar dari kerusakan kulit.

Dengan adanya tren perawatan kulit tersebut tak ayal banyak pelaku usaha (baik itu pelaku usaha kecil maupun pelaku usaha besar) yang memanfaatkan hal ini untuk melakukan kecurangankecurangan demi mendapatkan keuntungan yang besar, seperti menambahkan bahan - bahan berbahaya kedalam produk mereka seperti mercury yang melebihi batas, tidak mencantumkan secara lengakap komposisi yang digunakan, sampai dengan tidak mendaftarkan perizinan untuk produk mereka ke-BPOM, sehingga tidak mencantumkan Nomer izin edar BPOM dalam kemasan produk mereka.

Fungsi dari pendaftaran produk kosmetik keBPOM sendiri sangatlah penting untuk mengetahui produk tersebut aman digunakan atau tidak, sehingga tidak akan memicu kerusakan kulit yang berbahaya di kemudian hari bagi konsumen. Menurut Peraturan Menteri Kesehatan Nomor 1175/Menkes/Per/XII/2010 tentang Notifikasi Kosmetika "Produk kosmetik yang tidak memiliki nomor izin edar dari BPOM ini mencirikan bahwa produk kosmetik tersebut tidak aman untuk digunakan karena tidak melalui tahap uji laboratorium sebagai salah satu tahap untuk memperoleh nomor izin edar""1.

Dengan adanya penyebab inilah Konsumen dihimbau untuk lebih berhati - hati dalam memilih dan menggunakan produk-produk kosmetik, setidaknya sebelum konsumen membeli produk kosmetik, lihat komposisi dan kemasannya terlebih dahulu apakah mengandung bahan bahan berbahaya dan ada nomor izin edar dari BPOM atau tidak, karena dengan adanya nomor izin edar dari BPOM ini dapat di pastikan bahwa kosmetik yang di peredarkan di pasaran sudah lulus tes uji laboratorium dan aman untuk digunakan oleh konsumen. Berikut ini adalah data dari beberapa produk kosmetik ilegal yang tidak terdaftar nomor izin edarnya di-BPOM Semarang pada tahun 2018.

Tabel 1

Data produk kosmetik ilegal yang tidak terdaftar nomor izin edarnya di-BPOM tahun 2018

\begin{tabular}{|c|c|c|c|c|c|}
\hline & & & & & \\
\hline \multirow{3}{*}{$\begin{array}{l}\mathbf{N} \\
\mathbf{O}\end{array}$} & \multirow{3}{*}{$\begin{array}{c}\text { Nama } \\
\text { Produ k }\end{array}$} & \multirow{3}{*}{$\begin{array}{c}\text { Nama } \\
\text { Produsen }\end{array}$} & \multirow{3}{*}{$\begin{array}{c}\text { Alas } \\
\text { an Pena } \\
\text { rikan }\end{array}$} & \multirow{3}{*}{$\begin{array}{c}\text { Negara } \\
\text { Pemberi } \\
\text { Informas }\end{array}$} & \multirow{2}{*}{$\begin{array}{c}\text { Ketera } \\
\text { gan Izin Eda }\end{array}$} \\
\hline & & & & & \\
\hline & & & & & ya \\
\hline \multirow[t]{2}{*}{1.} & Nuriz & Progressiv & Men & Malaysia & Tidak \\
\hline & hopp e-UVE & e Mix & hndung & & ernot ifikasi \\
\hline
\end{tabular}

\footnotetext{
${ }^{1}$ http://digilib.unila.ac.id/56092/3/3.\%20SKRIPSI\% 20FULL\%20TANPA\%20BAB\%20PEMBAHASAN.p df diakses pada 6 januari 2020
}

\begin{tabular}{|c|c|c|c|c|c|}
\hline & $\begin{array}{l}\text { Pearl } \\
\text { Cream }\end{array}$ & & Merk uri & & \\
\hline 2. & $\begin{array}{l}\text { Nuriz- } \\
\text { D'solv e }\end{array}$ & $\begin{array}{l}\text { Progressiv e } \\
\text { Mix } \\
\text { Industries }\end{array}$ & $\begin{array}{c}\text { Men } \\
\text { gand } \\
\text { ung } \\
\text { Merk ur }\end{array}$ & Malaysia & $\begin{array}{c}\text { Tidak } \\
\text { Ternot } \\
\text { ifikasi }\end{array}$ \\
\hline 3. & $\begin{array}{l}\text { NV Anti } \\
\text { Blemis h } \\
\text { Toner } \\
1\end{array}$ & $\begin{array}{l}\text { QEMRICH } \\
\text { SDN. BHD. }\end{array}$ & $\begin{array}{c}\text { Men } \\
\text { gand } \\
\text { ung Hid } \\
\text { okin on } \\
\text { dan } \\
\text { Treti } \\
\text { noin }\end{array}$ & Malaysia & $\begin{array}{l}\text { Tidak } \\
\text { Ternot } \\
\text { ifikasi }\end{array}$ \\
\hline 4. & $\begin{array}{c}\text { Karism a } \\
\text { Cosme tic- } \\
\text { Night } \\
\text { Cream }\end{array}$ & NA & $\begin{array}{c}\text { Men } \\
\text { gand } \\
\text { ung } \\
\text { Merk ur }\end{array}$ & $\begin{array}{c}\text { Brunei } \\
\text { Darussal am }\end{array}$ & $\begin{array}{c}\text { Tidak } \\
\text { Ternot } \\
\text { ifikasi }\end{array}$ \\
\hline
\end{tabular}

Sumber Data : Badan-POM (Tribunnews.com)

Dengan adanya data diatas, disinilah peran pemerintah (yang dilakukan oleh BPOM) dibutuhkan dalam menangani peredaran kosmetik yang tidak terdaftar perizinannya di BPOM sendiri. Pemerintah bertanggung jawab atas pembinaan dan penyelenggaraan perlindungan konsumen yang menjamin diperolehnya hak konsumen dan pelaku usaha serta dilaksanakannya kewajiban konsumen dan pelaku usaha.

Di dalam penjelasan umum Undang- Undang Nomor 8 Tahun 1999 tentang Perlindungan Konsumen "disebutkan bahwa piranti hukum yang melindungi konsumen tidak dimaksudkan untuk mematikan usaha para pelaku usaha, tetapi justru mendorong iklim berusaha yang sehat, serta lahirnya perusahaan tangguh dalam menghadapi persaingan melalui penyediaan barang dan/atau jasa yang berkualitas"2. Pemerintah dalam upaya perlindungan konsumen mempunyai peran yang penting selaku penengah diantara kepentingan pelaku usaha dan kepentingan konsumen, agar masing-masing pihak dapat berjalan seiring tanpa saling merugikan satu sama lain ${ }^{3}$.

Dengan adanya Latar Belakang diatas dan data dari beberapa produk kosmetik yang tidak terdaftar izin edarnya di-BPOM Semarang, medorong penulis untuk menyusun skripsi dengan judul "PERLINDUNGAN KOSUMEN TERHADAP PRODUK KOSMETIK YANG TIDAK TERDAFTAR IZIN EDARNYA DI BPOM SEMARANG”.

2 Gunawan Widjaja, 2000, Hukum Tentang Perlindungan Konsumen, Cetak Pertama, Jakarta: Gramedia Pustaka Utama, hlm. 17

3 http://digilib.unila.ac.id/56092/3/3.\%20SKRIPSI\% 20FULL\%20TANPA\%20BAB\%20PEMBAHASA N.pdf Diakses pada 8 Januari 2020 


\section{Rumusan Masalah}

1. Bagaimana Perlindungan Hukum Bagi Konsumen Yang Menggunakan Produk

\section{Metode Penelitian}

\section{Tipe Penelitian}

Metode penelitian yang digunakan adalah pendekatan yuridis normatif ${ }^{4}$. Metode pendekatan yuridis normatife merupakan suatu pendekatan yang dilakukan berdasarkan bahan hukum utama dengan cara menelaah teori-teori, konsep-konsep, asas-asas hukum serta peraturan perundang-undangan yang berhubungan dengan penelitian ini.

\section{Spesifikasi Penelitian}

Jenis penelitian yang akan diteliti adalah penelitian Deskriptif analitis, yaitu cara memaparkan keadaan objek yang diteliti berdasarkan fakta-fakta dan data-data yang actual pada saat ini ${ }^{5}$.

\section{Sumber Data}

Jenis data yang digunakan dalam penelitian ini adalah sebagai berikut :

1. Data Sekunder

Adapun data sekunder dalam penelitian ini adalah :

1) Undang-Undang Nomor 8 Tahun 1999 Tentang Perlindungan Konsumen;

2) Undang-Undang Kesehatan Nomor 36 tahun 2009

3) Keputusan Presiden (Keppres) nomor 103 tahun 2001 tentang Kedudukan, Tugas, Fungsi, Kewenangan, Susunan Organisasi dan Tata Kerja Lembaga Pemerintah Non Departemen;

4) Peraturan Menteri Kesehatan Nomor 1175/Menkes/Per/XII/2010 Tentang Notifikasi Kosmetik;

5) Keputusan Kepala BPOM No.HK.00.05.4.175 Tentang Kosmetik

6) KUHP;

7) Buku - Buku dan Jurnal tentang Perlindungan Konsumen.

2. Data Primer

Data primer ini hanya sebagai pelengkap dari data sekunder, Data primer merupakan sejumlah keterangan atau fakta yang diperoleh secara langsung melalui penelitian lapangan.

\section{Metode Pengumpulan Data} meliputi :

Teknik pengumpulan data yang digunakan

1) Studi Kepustakaan:

Yaitu kegiatan pengumpulan data yang dilakukan dengan cara mempelajari bahanbahan tertulis.

\footnotetext{
4 Soerjono Soekanto \& Sri Mamudji, Penelitian Hukum Normatif, Jakarta : PT Raja Grafindo Persada, 2014, Cet : 16.

${ }^{5}$ Barda, Nawawi, Arief, 1992, Instrumen Penelitian Bidang Sosial, Yogyakarta, Gajah Mada University Press, hlm. 47.
}

2) Wawancara (sebagai pelengkap data): Yaitu pengumpulan data dengan cara mengadakan Tanya jawab secara langsung denganresponden yang berhubungan dengan objek penelitian.

\section{Metode Analisis Data}

Metode yang digunakan dalam menganalisis dan mengolah data-data yang terkumpul adalah analisis kualitatif ${ }^{6}$.

\section{Pembahasan}

\section{Perlindungan Hukum Bagi Konsumen Yang menggunakan Produk Kecantikan Yang Tidak Terdaftar Izin Edarnya Di BPOM Semarang}

\section{Perlindungan Berdasarkan Undang- Undang Perlindungan Konsumen}

Pemerintah berwenang melakukan pengawasan terhadap perlindungan konsumen sesuai yang tercantum dalam Pasal 30 Undang- Undang Perlindungan Konsumen Nomer 8 Tahun 1999, yang menyatakan :

1. Pengawasan terhadap penyelenggaraan perlindungan konsumen serta penerapan ketentuan peraturan perundang undangannya diselenggarakan oleh pemerintah, masyarakat, dan lembaga perlindungan konsumen swadaya masyarakat;

2. Pengawasan oleh pemerintah sebagaimana dimaksud pada ayat (1) dilaksanakan oleh menteri atau menteri teknis terkat;

3. Pengawasan oleh masyarakat dan lembaga perlindungan konsumen swadaya masyarakat dilakukan terhadap barang atau jasa yang beredar di pasaran;

4. Apabila hasil pengawasan sebagaimana dimaksud pada ayat (3) ternyata menyimpang dari peraturan perundang - undangan yang berlaku dan menyebabkan konsumen, menteri atau menteri teknis mengambil tindakan sesuai dengan peraturan perundang - undangan yang berlaku;

5. Hasil pengawasan yang diselenggarakan masyarakat dan lembaga perlindungan konsumen swadaya masyarakat dapat disebar luaskan kepada masyarakat dan dapat disampaikan kepada menteri atau menteri teknisi;

6. Ketentuan pelaksanaan tugas pengawasan sebagaimana dimaksud pada ayat (1), ayat (2), dan ayat (3) ditetapkan dengan peraturan pemerintah.

Dengan adanya pengawasan dari pemerintah apabila konsumen produk kosmetikmerasa dirugikan atas perbuatan curang yang dilakukan 
oleh pelaku usaha, menurut Pasal 45 UndangUndang Perlindungan Konsumen Nomor 8 Tahun 1999 konsumen dapat menggugat pelaku usaha melalui lembaga yang bertugas menyelesaikan sengketa antara konsumen dan pelaku usaha yaitu Badan Penyelesaian Sengketa Konsumen (BPKS). Tugas dan wewenang Badan Penyelesaian Sengketa Konsumen meliputi ${ }^{7}$ :

a. Melaksanakan penanganan dan penyelesaian sengketa konsumen dengan cara melalui mediasi atau arbitrase atau konsiliasi;

b. Memberikan konsultasi perlindungan konsumen;

c. Melakukan pengawasan terhadap pencantuman klausula baku;

d. Melaporkan kepada penyidik umum apabila terjadi pelanggaran ketentuan dalam UndangUndang ini;

e. Menerima pengaduan baik tertulis maupun tidak tertulis, dari konsumen tentang terjadinya pelanggaran terhadap perlindungan konsumen;

f. Melakukan penelitian dan pemeriksaan sengketa perlindungan konsumen;

g. Memanggil pelaku usaha yang diduga telah melakukan pelanggaran terhadap perlindungan konsumen;

h. Memanggil dan menghadirkan saksi, saksi ahli dan/atau setiap orang yang dianggap mengetahui pelanggaran terhadap Undangundang itu;

i. Meminta bantuan penyidik utuk menghadirkan pelaku usaha, saksi, saksi ahli, atau setiap orang sebagaimana dimaksud pada huruf g dan huruf $h$, yang tidak bersedia memenuhi panggilan badan penyelesaian sengketa konsumen;

j. Mendapatkan, meneliti dan/atau menilai surat, dokumen, atau alat bukti lain guna penyelidikan dan/atau pemeriksaan;

k. Memutuskan dan menetapkan ada atau tidak adanya kerugian di pihak konsumen;

1. Memberitahukan putusan kepada pelaku usaha yang melakukan pelanggaran terhadap perlindungan konsumen;

m. Menjatuhkan sanksi administratif kepada pelaku usaha yang melanggar ketentuan Undang-undang ini.

Penyelesaian sengketa dapat ditempuh melalui pengadilan atau diluar pengadilan berdasarkan pilihan sukarela para pihak yang bersengketa.Menurut Pasal 47 Undang-Undang Perlindungan Konsumen Nomor 8 Tahun 1999 "penyelesaian sengketa konsumen diluar pengadilan diselenggarakan untuk mencapai kesepakatan mengenai bentuk dan besarnya ganti rugi dan/atau tidak akan terulang kembali kerugian yang diderita oleh konsumen". Sedangkan menurut Pasal 48 Undang-Undang Perlindungan Konsumen Nomor 8 Tahun 1999 "penyelesaian sengketa konsumen melalui pengadilan mengacu

\footnotetext{
${ }^{7}$ Pasal 52 Undang-Undang Perlindungan Konsumen Nomor 8 Tahun 1999
}

pada ketentuan tentang peradilan umum yang berlaku".

Berdasarkan Pasal 46 ayat (1) Undang-Undang Perlindungan Konsumen Nomor 8 Tahun 1999 gugatan atas pelanggaran pelaku usaha dapat dilakukan oleh konsumen, ahli waris konsumen, LPKSM, pemerintah /instansi yang terkait.

\section{Perlindungan Berdasarkan Undang- Undang Kesehatan}

Menurut Undang-Undang Kesehatan, kosmetik termasuk dalam jenis sediaan farmasi, dalam Pasal 98 ayat (1) "Sediaan farmasi (termasuk kosmetik) harus aman berkhasiat/bermanfaat, bermutu, dan terjangkau", Sehingga dalam memproduksi suatu kosmetik pelaku usaha harus memenuhi standar dan persyaratan yang ditentukan oleh pemerintah ${ }^{8}$.

Dalam Pasal 106 ayat (1) "Sediaan farmasi (termasuk kosmetik) hanya dapat diedarkan setelah mendapat Izin edar". Hal ini bertujuan agar msayarakat dapat terlindungi dari produk-produk kosmetik yang berbahaya. Sehingga memproduksi dan menjual produk kosmetik yang tidak mendapat sertifikat mutu dan izin edar dari BPOM merupakan pelanggaran hukum dan dapat dikenakan sanksi ${ }^{9}$.

\section{Perlindungan Dari BPOM}

Untuk mengembangkan upaya perlindungan konsumen, dibentuklah BPOM atas Keputusan Presiden (Keppres) nomor 103 tahun 2001 tentang Kedudukan, Tugas, Fungsi, Kewenangan, Susunan Organisasi dan Tata Kerja Lembaga Pemerintah Non Departemen, dimana BPOM mempunyai tugas untuk melakukan kebijakan di bidang pengawasan Obat sesuai dengan ketentuan peraturan perundang-undangan.

Sistem pengawasan obat dan makanan yang diselenggarakan oleh BPOM merupakan suatu proses yang komprehensif, mencakup pengawasan pre-market dan post-market yang artinya BPOM telah melakukan pengawasan yang dilakukan sejak produsen memproduksi produk atau pengusaha yang mengimpor barang dari luar negeri. Setiap kosmetik yang beredar di dalam negeri baik yang diproduksi sendiri atau impor harus mengajukan notifikasi ke BPOM sebagai upaua Premarket Control. Setelah produk beredar BPOM juga akan melakukan pengetesan dan audit di sarana produksi.

Deputi II Pengawasan Obat tradisonal, suplemen kesehatan, dan kosmetik BPOM telah melakukan pengawasan secara optimal, dengan memastikan kosmetik yang tidak memiliki izin edar ditarik dari peredaran di pasaran. Tak hanya pengawasan secara konvensional seperti sidak ke toko atau swalayan, bersama kepolisian BPOM melakukan patroli siber untuk memastikan tidak ada kosmetik ilegal yang diedarkan melalui media sosial.

\footnotetext{
8 Pasal 105 Ayat (2) Undang - Undang Kesehatan Nomor 36 Tahun 2009 Tentang Kesehatan ${ }^{9}$ https://smartlegal.id diakses pada 11 juli 2020 


\section{Akibat Hukum Bagi Pelaku Usaha Kosmetik Yang Tidak Mendaftarkan Izin Edar Produknya Ke-BPOM Semarang}

Dalam menjalankan suatu usaha dalam pasal 7 Undang-Undang Perlindungan Konsumen, pelaku usaha kosmetik berkewajiban untuk menjalankan usahanya dengan jujur, dalam memproduksi suatu produk kosmetik sesuai dengan cara pembuatan kosmetik yang baik (CPKB) dan memberikan informasi produk yang benar dan jelas mengenai kondisi dan bahan yang terkandung didalamnya.

Jika pelaku usaha melakukan perbuatan yang dilarang dalam pasal 8 Undang-Undang Perlindungan Konsumen maka pelaku usaha wajib bertanggung jawab sesuai dengan Pasal 19 UndangUndang Perlindungan Konsumen menyatakan "Pelaku usaha bertanggung jawab memberikan ganti rugi atas kerusakan, dan/atau kerugian konsumen akibat mengkonsumsi barang dan/atau jasa yang dihasilkan atau diperdagangkan", Ganti rugi yang diberikan dapat berupa pengembalian uang atau penggantian barang dan/atau jasa.

Apabila pelaku usaha ada yang tidak mau melakukan pertanggung jawaban seperti yang tercantum diatas, maka BPSK dapat meberikan sanksi yang tercantum dalam undang-undang yang berlaku.

Dalam Pasal $60 \quad$ Undang-Undang Perlindungan Konsumen Nomor 8 Tahun 1999, Sanksi Administratif yang diberikan kepada pelaku usaha berupa penetapan ganti rugi paling banyak Rp.200.000.000,00 (dua ratus juta rupiah).

Sedangkan Sanksi Administratif menurut Pasal 47 Ayat (2) Peraturan Badan Pengawas Obat Dan Makanan Nomor 12 Tahun 2020, berupa Peringatan tertulis, Pencabutan notifikas, Penutupan akses daring pengajuan permohonan notifikasi paling lama 1 (satu) tahun; dan Penutupan akses daring pengajuan permohonan surat keterangan impor paling lama 1 (satu) tahun.

Menurut Pasal 20 Peraturan Menteri Kesehatan Nomor 1175 /Menkes/Per/XII/2010 Tentang Notifikasi Kosmetik, Sanksi Administratif yang diberikan kepada pelaku usaha berupa Larangan mengedarkan untuk sementara waktu dan/atau perintah untuk penarikan kembali produk dari peredaran, Perintah pemusnahan produk, Penghentian sementara kegiatan, Pembekuan izin produksi, dan Pencabutan izin produksi

Sanksi Pidana berdasarkan Pasal 196 Undang-Undang Kesehatan Nomor 36 Tahun 2009 "pelaku usaha kosmetik yang tidak memenuhi standar keamanan, khasiat dan mutu dapat dipenjara 10 tahun dan denda Rp. 1.000.000.000,00 (satu miliar rupiah)". Sedangkan berdasarkan Pasal 197 "pelaku usaha kosmetik yang tidak memiliki izin edar bisa dipenjara 15 tahun dan didenda 1.500.000.000,00 (satu koma lima miliar rupiah)". Sanksi Pidana yang tercantum dalam Pasal 62 Undang-Undang Perlindungan Konsumen berupa pidana penjara paling lama 5 (lima) tahun atau Pidana denda Paling banyak Rp.2.000.000.000,00 (dua miliar rupiah);
Data Beberapa Kosmetik Yang Di Sita BPOM Karena Tidak Terdaftar Izin Eadrnya Pada Tahun 2019 Di Kota Semarang

\begin{tabular}{|c|c|c|c|}
\hline No. & $\begin{array}{c}\text { Nama } \\
\text { Produk }\end{array}$ & Keterangan & Status \\
\hline $\mathbf{1 .}$ & $\begin{array}{c}\text { RDL } \\
\text { Hidroquino } \\
\text { ne Tretinoin } \\
\text { Babyface }\end{array}$ & $\begin{array}{c}\text { Mengandung } \\
\text { Bahan } \\
\text { Berbahaya }\end{array}$ & Tidak \\
Ternotifikasi \\
\hline $\mathbf{2 .}$ & $\begin{array}{c}\text { Original DR } \\
\text { Pemutih } \\
\text { Dokter }\end{array}$ & $\begin{array}{c}\text { Mengandung } \\
\text { Bahan } \\
\text { Berbahaya }\end{array}$ & Tidak \\
& Ternotifikasi \\
\hline $\mathbf{3 .}$ & $\begin{array}{c}\text { Deonard } \\
\text { Whitening } \\
\text { \& Spot } \\
\text { Removing }\end{array}$ & $\begin{array}{c}\text { Mengandung } \\
\text { Bahan } \\
\text { Berbahaya }\end{array}$ & $\begin{array}{c}\text { Tidak } \\
\text { Ternotifikasi }\end{array}$ \\
\hline $\mathbf{4 .}$ & $\begin{array}{c}\text { Temulawak } \\
\text { Cream Night } \\
\text { Cream }\end{array}$ & $\begin{array}{c}\text { Mengandung } \\
\text { Bahan } \\
\text { Berbahaya }\end{array}$ & Tidak \\
& Ternotifikasi \\
\hline $\mathbf{5 .}$ & $\begin{array}{c}\text { RDL Pepaya } \\
\text { Whitening } \\
\text { Soap }\end{array}$ & $\begin{array}{c}\text { Mengandung } \\
\text { Bahan } \\
\text { Berbahaya }\end{array}$ & Tidak \\
& Ternotifikasi \\
\hline
\end{tabular}

Sumber : www.pom.go.id (Berita, Siaran Pers)

Solusi Yang Diberikan Kepada Pelaku
Usaha dan Konsumen Dalam Menangani
Permasalahan Izin Edar BPOM
Semarang

\section{Pembinaan Pemerintah Berdasarkan Undang-Undang Perlindungan Konsumen}

Untuk mengurangi resiko terjadinya kecurangan yang dilakukan pelaku usaha dan untuk mencegah terjadinya kerugian bagi konsumen, menurut Pasal 29 Undang-Undang Perlindungan Konsumen Nomor 8 Tahun 1999 dapat dilakukan pembinaan. Dimana pemerintah bertanggung jawab atas pembinaan penyelenggaraan perlindungan konsumen untuk menjamin diperolehnya hak dari konsumen dan pelaku usaha serta dilaksanakannya kewajiban dari konsumen dan kewajiban dari pelaku usaha. Pembinaan yang dilakukan oleh pemerintah dalam penyelenggaraan perlindungan konsumen dilakukan oleh menteri atau menteri teknisi terkait.

\section{Solusi Dari BPOM Semarang}

BPOM Semarang selaku badan pengawasan obat dan makanan memberikan solusi kepada konsumen dan juga pelaku usaha guna mencegah terjadinya pelanggaran dalam perlindungan konsumen. Solusi yang diberikan BPOM terhadap pelaku usaha berupa pembinaan, Apabila pembinaan yang dilakukan oleh bpom tidak ditaati atau dilanggar oleh pelaku usaha maka BPOM melakukan Proses penindakan, apabila proses penindakan ini tetap dilanggar oleh pihak pelaku usaha, maka pelaku usaha akan berstatus sebagai Residivis ${ }^{10}$. 
BPOM Semarang juga melakukan kegiatan survey pasar dalam rangka implementasi pasar aman dari bahan-bahan berbahaya serta dari produk kosmetik yang tidak ada nomor izin edarnya. Kegiatan yang dilakukan guna memonitoring program pengawasan keamanan produk-produk yang dijual di pasar.

\begin{tabular}{|c|c|c|c|}
\hline No & $\begin{array}{c}\text { Nomor } \\
\text { Registrasi }\end{array}$ & Produk & Pendaftar \\
\hline 1. & $\begin{array}{l}\text { NA18201203258 } \\
\text { Terbit : 02-07- } \\
2020\end{array}$ & $\begin{array}{l}\text { Honey } \\
\text { Micellar } \\
\text { Water } \\
\text { Merk : } \\
\text { LUHUR } \\
\text { Kemasan : } \\
\text { Botol } 60 \mathrm{ml} \text {, } \\
\text { Botol } 100 \mathrm{ml}\end{array}$ & $\begin{array}{l}\text { ARYATI, CV } \\
\text { Kab Demak, } \\
\text { Jawa Tengah }\end{array}$ \\
\hline 2. & $\begin{array}{l}\text { NA18201203259 } \\
\text { Terbit : 02-07- } \\
2020\end{array}$ & $\begin{array}{l}\text { Toner Face } \\
\text { Two In One } \\
\text { Merk : } \\
\text { LUHUR }\end{array}$ & $\begin{array}{l}\text { ARYATI, CV } \\
\text { Kab Demak, } \\
\text { Jawa Tengah }\end{array}$ \\
\hline & & $\begin{array}{l}\text { Kemasan : Botc } \\
\text { hl, Botol } 100 \mathrm{ml}\end{array}$ & \\
\hline 3. & $\begin{array}{l}\text { NA18200104642 } \\
\text { Terbit : 02-07- } \\
2020\end{array}$ & $\begin{array}{l}\text { Night Cream } \\
\text { k: MAZA SKINCAF } \\
\text { hasan: Tube } 75 \mathrm{~m} \\
\text { e } 200 \mathrm{ml}\end{array}$ & $\begin{array}{c}\text { Zweena Adi } \\
\text { Fraha, CV Kota } \\
\text { akarta, Jawa Teng }\end{array}$ \\
\hline 4. & $\begin{array}{l}\text { NA18200104643 } \\
\text { Terbit : 02-07- } \\
2020\end{array}$ & $\begin{array}{l}\text { Day Cream Mel } \\
\text { ENG MEDICAL } \\
\text { ITER Kemasan : Pe } \\
\text { \$, Pot } \\
12 \mathrm{~g} \text {, Pot } 5 \mathrm{~g} \text {, } \\
\text { Pot } 15 \mathrm{~g}\end{array}$ & $\begin{array}{l}\text { Zweena Adi } \\
\text { raha, CV Kota } \\
\text { akarta, Jawa Teng }\end{array}$ \\
\hline 5. & $\begin{array}{l}\text { NA18201700737 } \\
\text { Terbit : 02-07- } \\
2020\end{array}$ & \begin{tabular}{|l|} 
Sunscreen \\
wing Oil Free \\
Merk: \\
DERMAGLOW \\
asan: Pot \\
$12.5 \mathrm{~g}$
\end{tabular} & $\begin{array}{l}\text { HERMANTO } \\
\text { YA ESTETIKA, PT } \\
\text { Sragen, Jawa } \\
\text { gah }\end{array}$ \\
\hline 6. & $\begin{array}{l}\text { NA18201000767 } \\
\text { Terbit : 02-07- } \\
2020\end{array}$ & $\begin{array}{c}\text { 2in1 Shampo } \\
\text { k: RYER Kemasan } \\
\text { ol } 100 \mathrm{ml} \text {, Botol } \\
0 \mathrm{ml} \text {, Botol } 125 \mathrm{~m} \\
\text { l } 15 \mathrm{ml} \text {, Botol } 20\end{array}$ & $\begin{array}{l}\text { BUKIT PERAK, } \\
\text { Kota Semarang } \\
\text { a Tengah }\end{array}$ \\
\hline
\end{tabular}

\section{Kesimpulan dan Saran}

\section{Kesimpulan}

Perlindungan hukum bagi konsumen yang menggunakan kosmetik tanpa izin edar dari BPOM, diatur dalam

1. Psl 30, Psl 45, dan Psl 46 Ayat (1) UUPK No.8 Thn 1999;

2. Psl 98 Ayat (1), dan Psl 106 Ayat (1) UUKesehatan No. 36 Thn 2009
Akibat hukum bagi pelanggar izin edar dapat dikenakan sanksi, berupa sanksi administratif dan sanksi pidana sesuai yang diatur dalam, UUPK No.8 Thn 1999, Peraturan BPOM No.12 Thn 2020, Peraturan Menteri Kesehatan No.1175/Menkes/Per/XII/2010, UUKesehatan Nomor 36 Thn 2009.

Solusi yang diberikan kepada pelaku usaha dan konsumen

1. Untuk Pelaku usaha Sebelum memperedarkan produk kosmetik yang dihasilkannya di pasaran, pelaku usaha dianjurkan untuk mendaftarkan produk kosmetiknya ke BPOM;

2. Untuk Konsumen disarankan menggunakan produk kosmetik yang telah diterdaftar izin edarnya diBPOM

Saran

1. Dalam pembuatan kosmetik hendaknya pelaku usaha mengikuti sesuai dengan cara pembuatan kosmetik yang baik (CPKB) agar pelaku usaha tidak merugikan konsumen, dan pelaku usaha akan terhindar dari pelanggaran hukum;

2. Konsumen yang menggunakan produk kosmetik, lebih baik tidak memilih kosmetik yang dapat membuat kult putih bersih secara instan, tetapi konsumen lebih baik memilih ada nomor izin edarnya dari BPOM.

3. Hendaknya BPOM selaku Badan Pengawas Obat dan Makanan di seluruh indonesia lebih meningkatkan pengawasannya, karena diluaran sana masih banyak terdapat kosmetik yang tidak berizin yang di jual bebas di pasaran.

4. BPOM selaku Badan Pengawas Obat dan Makanan memberikan sosialisasi dan penyuluhan kepada konsumen agar menggunakan produk yang telah terdaftar nomor izinnya di BPOM. Karena diluaran sana masih banyak konsuemn yang tidak memahami arti dari nomor izin edar ini.

\section{Daftar Pustaka}

\section{Literatur}

Barda, Nawawi, Arief, 1992, Instrumen Penelitian Bidang Sosial, Yogyakarta, Gajah Mada University Press

Gunawan Widjaja, 2000, Hukum Tentang Perlindungan Konsumen, Cetak Pertama, Jakarta: Gramedia Pustaka Utama

Lilik Pujiastutik, Perizinan Sebagai Instrumen Perlindungan Hukum Dalam Peredaran Kosmetik Yang Aman Dalam Masyarakat,

Soerjono Soekanto \& Sri Mamudji, Penelitian Hukum Normatif, Jakarta : PT Raja Grafindo Persada, 2014

Sugiyono, "Metode Penelitian Kuantitatif, Kualitatif, dan R\&D”, (Bandung: CV. Alfabeta,2017) 


\section{Peruundang-Undangan}

Undang - Undang Kesehatan Nomor 36 Tahun 2009 Tentang Kesehatan

Peraturan Badan Pengawas Obat Dan Makanan Nomor 12 Tahun 2020 Tentang Cara Pengajuan Notifikasi Kosmetik

Peraturan Menteri Kesehatan Nomor 1175/Menkes/Per/XII/2010 Tentang Notifikasi Kosmetik

Undang - Undang Perlindungan Konsumen Nomor 8 Tahun 1999

\section{Website}

htip:/dipilib.unila.ac.id/56092/3/3.\%20SKRIPSI\%20FUL L\%20TANPA\%20BAB\%20PEMBAHASAN.pdi akses pada 6 januari 2020

https://smartlegal.id diakses pada 11 juli 2020 pukul $07.40 \mathrm{~W}$ 